\title{
La neutralización del arte: ¿un destino inevitable? ${ }^{1}$
}

\author{
GERARD VILAR \\ Universidad Autónoma de Barcelona
}

UN FANTASMA RECORRE EL MUNDO DEL ARTE contemporáneo, un fantasma burlador, sutil y traicionero, un fantasma que ante nuestros ojos transfigura el Arte en arte, el fantasma de la neutralización. Las obras que quisieron o aún quieren cambiar el mundo, así las que quieren desbordarlo desde dentro como aquellas que se le oponen frontalmente y lo fustigan y condenan, acaban recicladas como arte fetichizado, esto es, como mercancía, como imagen estetizada, coleccionable y museable, depotenciada en el mejor de los casos de buena parte o incluso toda su fuerza crítica y subversiva. Pensemos en las obras críticas, exploradoras y subvertidoras de una Ana Mendieta o de un Leon Golub, de Barbara Kruger o de Jenny Holzer. Más allá de las intenciones originarias de dichos artistas, ¿hay hoy alguna diferencia entre un Mendieta o un Golub y un Koons o un Murakami? Las fotografías de Mendieta en una supuesta situación de violación son hoy en día objeto de un selecto tráfico comercial de la mano de la Gallerie LeLong, una de las más distinguidas galerías neoyorquinas que sólo comercia con los nombres más cotizados. Cualquier rico coleccionista puede hoy comprarse esas fotografías de Mendieta para colgarlas en su salón o su estudio en la seguridad que ha hecho una buena inversión en una artista clásica del arte feminista de la primera fase del posmodernismo. «Compro, luego existo», una obra de Kruger crítica con el capitalismo sirve para ilustrar bolsas de compra de una tienda chic de diseño de lujo del Paseo de Gracia de Barcelona. Y las proyecciones luminosas de Jenny Holzer con sentencias políticamente críticas sirven para dar un toque de corrección a los espectáculos de las fiestas veraniegas de las ciudades cultas y distinguidas donde se consumen ríos de champán, toneladas de langosta y kilos de cocaína. Las obras de arte

1 Este artículo es parte del resultado del proyecto de investigación HUM2005-05757 financiado por el Ministerio de Educación y Ciencia. Agradezco a Félix de Azúa, Jéssica Jaques, Jordi Ibáñez, Marta Tafalla y Pol Capdevila el constante estímulo y sus reflexiones críticas. 
político se venden y compran como mercancías que son, acaban coleccionadas por agentes económicos privados como inversión y como símbolo de status, o se hallan expuestas en los centros de arte que se encuentran en todas las ciudades ricas y cultas del mundo, o con aspiraciones a serlo. Y hay otros fenómenos más sutiles. Las obras de aquellos artistas que entre los años sesenta y los ochenta, en ese extraño momento del acabamiento de las vanguardias, todavía tan oscuro para la teoría, aquellos artistas que se dedicaron a atacar el concepto dominante aún de arte aurático y que, como Robert Morris, Donald Judd o Richard Long, desplegaron su ingenio en una obra de resistencia y crítica, ven hoy sus obras coleccionadas y expuestas como los vermeers y los manets, fetiches objeto de culto. Incluso la obra de aquellos más refractarios y difíciles representantes de la «crítica institucional», Marcel Broodthaers o Georges Brecht, por ejemplo, quienes combatieron sin desfallecer las instituciones del mundo del arte, especialmente el museo, son objeto hoy de veneración en los grandes museos de arte contemporáneo que les organizan i «heterospectivas»!

Desde que el arte adquirió un potencial para cuestionar el orden de las palabras y de las cosas se ha podido observar que la fuerza crítica y turbadora de las obras podía menguar e incluso desaparecer con el tiempo y los cambios de contexto y circunstancias. La hermenéutica y la teoría de la recepción ya demostraron que los cambios en la recepción de las obras de todas las épocas y culturas son parte de su vida histórica y del proceso de constitución del sentido en el largo proceso de diálogo de éstas con cada nuevo horizonte generacional, epocal y cultural. Esto también ha pasado, obviamente, con las obras de arte moderno y de vanguardia. Las obras subversivas y radicales de los cubistas, los dadaístas o los conceptuales están hoy ennoblecidas y auratizadas y son reverenciadas en los museos donde las contemplamos con la misma mirada que las tablas flamencas o los cuadros rococó. Al cambiar el contexto político y social las obras de Rodchenko o de Tzara estaban igual de expuestas que las Venus romanas y las Madonnas renacentistas. Ya Hegel en su temprana Fenomenología del Espíritu (1807) sentenció que «las estatuas son ahora cadáveres cuya alma vivificadora se ha esfumado, así como los himnos son palabras de las que ha huido la fe... Las obras de las musas ya sólo son lo que son para nosotros: bellos frutos caídos del árbol... el destino ya no nos entrega con las obras de este arte su mundo, la primavera y el verano de la vida ética en las que florecen y maduran, sino solamente el recuerdo velado de esta realidad $»^{2}$. Si ese fuera el destino inevitable de todo arte crítico, social o políticamente comprometido, entonces la neutralización sería un fenómeno menos interesante de lo que es. Sin embargo, la verdad es que este destino no es inevitable: la obra crítica de Goya o la de Picasso, como las de Otto Dix, 
Dennis Hopper o Francis Bacon, conservan muy fresca su fuerza, aunque no esté muy claro por qué.

El arte contemporáneo, por su parte, parece condenado a la neutralización desde el mismo momento de su creación. Los fenómenos de la mercantilización, la cosificación, la banalización, la trivialización y las distintas variedades de la depotenciación hacen que hoy en día, paradójicamente, sea muy difícil hacer arte político, crítico y subversivo sin que sea engullido inmediatamente por los mecanismos de las instituciones que gestionan la exhibición y la subvención, el mercado y el espectáculo. Se hace, pues, imprescindible estudiar y comprender más a fondo los diferentes mecanismos por los que el potencial crítico del arte de hoy queda neutralizado y la imagen subvertidora se convierte en mera imagen estetizada con tanta facilidad. Para ello voy a proceder en tres pasos: primero voy a remontarme a la estética de Adorno, el primer teórico hasta donde se me alcanza en apercibirse de la importancia estructural del fenómeno de la neutralización ya en los años cincuenta del siglo pasado. A continuación, y en segundo lugar, me detendré en las reflexiones del joven Hal Foster en los años ochenta acerca de la necesidad de un cambio radical de estrategia por parte de los artistas empeñados en hacer arte político. Por último, me referiré a las reflexiones del crítico e historiador del arte Donald Kuspit acerca de la necesidad de combatir la fetichización y la reificación del arte por medio de una conciencia crítica que no se pliegue al relativismo postmoderno que sólo puede mirar el arte contemporáneo como un puzzle cuyas piezas no encajan.

Hagamos primero, pues, un poco de historia. Probablemente, el primero que vio con cierta seriedad y como un fenómeno estructural de la cultura tardomoderna fuera el filósofo alemán T. W. Adorno. Aun cuando Adorno reconoció y conceptuó, como es bien sabido, el poder de lo que denominó «industria cultural» a partir de los años treinta en las sociedades occidentales, no fue hasta los años sesenta, cuando empezó a resquebrajarse su confianza en la estrategia de resistencia del arte auténtico frente a la sociedad administrada y la cultura mercantilizada, que empezó una línea de reflexión autocrítica en torno a la posibilidad eventual de neutralización (Neutralisierung) de todo arte. Así, en su obra póstuma Teoría estética reconoce el problema abiertamente: las obras suelen actuar críticamente en el momento de su aparición; más tarde quedan neutralizadas debido al cambio de la situación. La neutralización es el precio social de la autonomía estética, porque una vez que las obras están sepultadas en el panteón de los bienes culturales, resultan dañadas en su contenido de verdad y en ellas mismas. «La neutralización es universal en el mundo admi- 
nistrado» ${ }^{3}$. El gran ejemplo inmediato es para Adorno el surrealismo, que se opuso a la fetichización del arte como una esfera aparte, pero que en la medida que era arte (pintura) fue conducido más allá de la pura figura de la protesta, de la piedra de escándalo, para someterse a la recepción de la sociedad, tal y como empezó a observarse relativamente en los casos de André Masson y de Salvador Dalí, convertidos, por el equilibrio que su obra busca entre subversión y aceptación social, en los Laszlo o los Van Dongen de su generación. Adorno sentenciaba a partir de este razonamiento la falsa pervivencia del surrealismo y, por extensión, la inevitable condena a la falsa reconciliación en la era de la neutralización total. Todas las corrientes modernas en las que contenidos que irrumpen como un shock socavaron la ley formal de la obra de arte están destinadas a pactar con el mundo. El penúltimo ejemplo sería el expresionismo abstracto, que tan bien queda como decoración de las paredes del nuevo bienestar de los cincuenta y sesenta.

Adorno, sin embargo, llegó a estos puntos de vista, no desde las artes visuales o la literatura sino a partir de su conocimiento y experiencia de la música contemporánea. Desde los años cincuenta, Adorno había constatado el problema del «envejecimiento de la música nueva». Esa música de la vanguardia más minoritaria y hermética defendida por Adorno con la expresión «música nueva» (Neue Musik) venía de principios de siglo. Se trataba de la segunda escuela vienesa encabezada por Arnold Schönberg y representada por Alban Berg y Anton Webern. A ella habría que añadir otros nombres menores como Ernst Krenek o el del propio Adorno, compositor a ratos perdidos desde que decidió, a finales de los años veinte, dedicarse profesionalmente a la filosofía y no a la música. Cuando a finales de los años cuarenta Adorno publica su Filosofía de la nueva música, resulta que esa «nueva música» es ya cuarentona. Claro, en la década siguiente, Adorno se topa con el problema de toda vanguardia: se ha institucionalizado, su fuerza subvertidora se ha consumido, los tiempos han cambiado, y lo que queda es, en caso de que la tuviere, la fuerza estética de la obra. Pero ésta ya no tiene por qué ser una fuerza crítica. La catástrofe de la Segunda Guerra Mundial prolongó de un modo evidente los gritos del sufrimiento humano que se encontraban en Erwartung op. 17 o en las Tres piezas para piano op. 11 de Schönberg hasta El superviviente de Varsovia op. 46 compuesto en el exilio americano de la postguerra en 1947. Pero la que avanzaba era la época del baby boom, del consumismo y del nuevo bienestar tan certeramente representada por el célebre collage de R. Hamilton Just What Is It That Makes Today’s Homes So Different, So Appealing? (¿Pero qué es lo que hace a los hogares de hoy día tan diferentes, tan atractivos?) presentado en 1956 en la Whitechapel Art Gallery de Londres. Los gritos de sufrimiento, 
los vacíos existencialistas ahogados en alcohol y las angustias por la extinción nuclear fueron progresivamente sustituidos por el rock and roll, los nuevos hedonismos y la venta a plazos. Aquella música que, según Adorno, había «tomado sobre sí todas las tinieblas y culpas del mundo» ${ }^{4}$, a imagen de Cristo y su promesa de redención, aquella música cuya inhumanidad debía «sobrepasar a la del mundo por mor de la humanidad», hasta convertirse en un «mensaje en la botella» condenado al olvido absoluto, aquella música ya había envejecido sin que, aparentemente, se hubieran cumplido las esperanzas de redención depositadas en su clausura hermética y su negatividad décadas atrás. Ya en 1955, Adorno constata que la autenticidad de la música nueva anda muy erosionada por su estabilización, por la perdida de su impulso, de su fuerza configuradora, y porque entra en contradicción con su idea y, por ello, pierde también su substancialidad estética y su temple ${ }^{5}$. No se llama a engaño: «En la nivelación y neutralización del material se hace palpable el envejecimiento de la Nueva Música, el carácter facultativo de un radicalismo que ya no cuesta nada. Y no cuesta nada en un doble sentido: ni espiritualmente, porque junto con el temor y la aversión ante tales acordes y el goce en ellos han desaparecido también su substancia, su fuerza expresiva, su relación con el sujeto; ni tampoco realmente, porque hoy día apenas si se irrita nadie contra el dodecafonismo, que tiene acceso a todas las solemnidades musicales» ${ }^{6}$.

En los últimos años de su vida a la categoría de neutralización le añadirá otra que, hasta cierto punto, sería sinónima de ésta: «desartificación» (Entkustung). Adorno la formuló por primera vez en «Moda sin tiempo», su famoso texto de mediados de los cincuenta sobre el jazz. En el jazz la música se desartifica ${ }^{7}$. Es decir, es música sometida a los imperativos de la mercancía que cumple la muy importante función de suministrar a la juventud un compromiso entre la sublimación estética y la adaptación social. Así el arte se convierte en un bien de consumo, una cosa donde el sujeto proyecta sus sentimientos y que actúa como vehículo psíquico para sus impulsos miméticos, con lo que pierde su razón de ser y se integra en el mundo de la industria cultural. Con ello tenemos una falsa liquidación del arte, esto es, que en lugar de realizarse la utopía ésta desaparece del texto. Unos años más tarde, en los sesenta del la eclosión del pop, se habría alcanzado una fase de «plena tendencia universal hacia la desartificación del

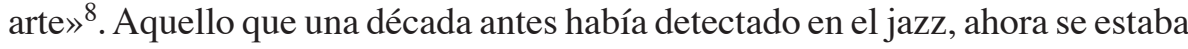

4 T. W. Adorno, Filosofía de la nueva música, Madrid: Akal, 2003, p. 119. GS 12, p. 126.

5 T. W. Adorno, Disonancias, Madrid: Rialp, 1966, pp. 156 ss.; GS 14, pp. 143 ss.

6 Idem, p. 164; p. 149.

7 T. W. Adorno, Prismas, Barcelona: Ariel, 1962, p. 140; GS 10.1, p. 136.

8 T. W. Adorno, Impromptus, Barcelona: Laia, 1985, p. 31; GS 17, p. 183. 
convirtiendo en norma. Su Introducción a la sociología de la música de 1968, ese año mágico, y obra fundamental en su campo y que todavía espera ser vertida al castellano, constata que la desartificación del arte se extiende al movimiento musical en general ${ }^{9}$, donde prolifera la «neutralización del arte convertido en bien cultural que se consume sin que se perciba el contenido estético que obliga a ir más allá del mismo» ${ }^{10}$. Aquella experiencia del «Debes cambiar tu vida» que, según los célebres versos de Rilke, nos produciría la contemplación del torso arcaico de Apolo, habría sido reprimida y anulada.

¿Es posible escapar a este destino según Adorno? Antes de morir inesperadamente en agosto de 1969, Adorno, un pesimista que se resistía con obstinación al pesimismo de sus propias posiciones, se aferró a los conceptos de «audición e interpretación estructurales», «objetivación de la vida musical», etc. Frente al «enmudecimiento» final de la música ${ }^{11}$, al que muchos de sus textos apuntaban, Adorno contempló honestamente la posibilidad que la situación agonal de la música culta y, por ende, de todas las artes, fuera un estado permanente sin resolución en uno u otro sentido. El «enmudecimiento» de la música, así, como el fin del arte en general, tan sólo sería una amenaza dialéctica que hace creíble el estado de resistencia y lucha permanentes. En el arte como en la música, tal y como se dice en el final de la novela El innombrable de Samuel Beckett «il faut continuer», hay que proseguir. Aunque al final todo arte y toda música vayan a ser derrotadas nos salvaría la resistencia, el empeño y la persistencia, al igual que el Fausto goetheano se salva al final por su esfuerzo. Al final, pues, Adorno se reencuentra con el mito romántico de la redención por el fracaso, un mito fundador de la modernidad que sigue sólidamente acomodado en el presente.

Las posiciones de Adorno en torno al problema de la neutralización adolecen de los problemas característicos de la estética negativa adorniana. De dichos y diversos problemas sólo me referiré aquí a dos: en primer lugar, la posición central y dominante del concepto de autonomía de la obra de arte y, en segundo lugar, el moralismo estético, por llamarle de algún modo, encierra una posición autoritaria en relación a la autenticidad y el pluralismo. Respecto a la primera cuestión, la de la autonomía de la obra de arte auténtica, hay que constatar como una limitación grave de la estética adorniana que se entienda que todo arte que merezca ese nombre debe ser autónomo. Esta es una posición tradicional del arte moderno a la que inevitablemente le llegó el momento de ser cuestionada, siguiendo la lógica misma de la modernidad estética, la lógica de la transgresión y la ruptura con todos las normas, los prejuicios y los límites

9 T. W. Adorno, Einleitung in die Musiksoziologie, GS 14, p. 85.

10 Idem, pp. 119-120.

$11 C f$. G. Vilar, «Enmudecimiento: Adorno y el fin de la música», en: M. Cabot (ed.), El pensamiento de Th.W. Adorno. Balance y perspectivas, Palma: UIB, 2007, pp. 137-144. 
aceptados. La negación de la autonomía de la obra de arte se convirtió progresivamente en un principio normativo para muchos artistas a partir de principios de los sesenta y es un principio común del arte contemporáneo. Desde muchas de las propuestas del pop, el conceptual y el accionismo de Andy Warhol, Marcel Broodthaers o Rudolf Schwarzkogler hasta Rirkit Tiravanija, Santiago Sierra o Vanessa Beecroft, la categoría de autonomía ya no designa una noción desde la que pensar el arte en general sino más bien el arte del pasado de Praxíteles a Picasso, o bien el de sus muy legítimos continuadores en el presente, llámense Gerhardt Richter o Miquel Barceló. Pero la estética negativa de Adorno no tiene gran cosa que decir del arte de Hans Haacke o de Sophie Calle, a pesar de ser obras con un fuerte contenido político y de crítica social. No lo tiene porque las obras de dichos artistas no están constituidas por un objeto autónomo que pueda pensarse y experimentarse en y desde su autonomía. Son instalaciones site-specific, o pensadas como intervención en el debate público de un cierto momento y lugar, o son completamente heterónomas respecto a las identidades y biografías de determinados sujetos y del propio artista. De otro lado, la estética negativa adorniana está demasiado aferrada a una concepción de la dialéctica del arte apegada a la tradición de Hegel y de Marx según la cual la negatividad es el momento verdadero de todo proceso de progreso frente al cual la positividad es lo falso. Al igual que en el marxismo todo arte o bien estaba del lado del proletariado y el socialismo o bien del lado de la burguesía y el capitalismo, Adorno piensa también que frente a la sociedad administrada sólo es legítima la obra autónoma negativa y toda otra opción está con el enemigo. Este moralismo estético que afloró con fuerza en sus discrepancias con Walter Benjamin de los años treinta, es el que le llevaría a condenar en bloque corrientes musicales como el jazz o incluso ¡el cine!, impidiéndole ver, entender y apreciar el pluralismo de las posiciones en el arte de los sesenta y del que habría de venir en décadas posteriores. Un par de años antes de fallecer, en 1967, Adorno, defendiendo su tesis de la audición y la interpretación «estructurales» escribe lo siguiente: «La apariencia de pluralismo, es decir, la ilusión de que fenómenos divergentes e irreconciliables entre sí -de la suma de los cuales se compone la vida musical hoy- tienen los mismos derechos, desaparecería tan pronto como la audición estructural percibiera de modo inmanente la calidad o la falta de calidad de las obras sin necesidad de recurrir a préstamos tomados de fuera. Si es cierto que no hay más que una verdad, entonces tampoco hay en la música más que una verdad» ${ }^{12}$. La teoría estética adorniana extiende esta comprensión de la música a la totalidad de las prácticas artísticas. La negación del pluralismo no sólo es una negación de la realidad y lo evidente en nombre de lo que debería

12 T.W. Adorno, «Anotaciones sobre la vida musical alemana», en: Impromptus, Barcelona: Laia, 1985, p. 35. GS, vol. 17, p. 187. 
ser, sino que tiene un núcleo autoritario, frecuente en las vanguardias y en los discursos sobre ellas -piénsese en Breton o en Greenberg-, que siempre opta por una concepción normativa del arte que resulta excluyente para las no elegidas o «condenadas». El moralismo adorniano, en su exigencia de justicia y de vida no dañada, resulta antidemocrático y no es fácil de conciliar con la irrenunciable noción de una esfera pública libre en la que el arte se presenta como un modo de crítica para pensar entre todos el mundo y como un elemento activo central en nuestros procesos de aprendizaje en el camino de la libertad, la igualdad y la solidaridad.

$\mathrm{Si}$, por consiguiente, el arte puede legítimamente ser autónomo o no serlo y no hay una sola verdad estética, sino que el arte se dice de muchas maneras y hay muchos modos distintos de ejercer la crítica de la sociedad, entonces el concepto de neutralización empleado por Adorno ha de emplearse con mucha más circunspección y cautela de lo que podríamos suponer. Pues, desde la perspectiva adorniana, aparecen como arte neutralizado muchas obras que acaso no lo sean, por el simple hecho de ser otro tipo de arte que aquel negativo y autónomo defendido por Adorno en los nombres emblemáticos de Picasso, Schönberg y Kafka.

La estética adorniana y su concepto de neutralización pertenecen a un periodo pasado del arte, la música y la literatura occidentales, la época clásica y heroica de las vanguardias. El final de esa época y la necesidad de plantearse otras concepciones y estrategias para el arte crítico fue uno de los grandes temas centrales de la discusión en torno a la postmodernidad desde finales de los años setenta y a lo largo de los ochenta. Las célebres intervenciones y polémicas entre Habermas, Lyotard, Jameson, Foster, Kuspit y otros sentenciaron un final relativo de la vanguardia, una continuidad con rupturas de la modernidad estética, un cambio en la percepción del tiempo y la historia, y, finalmente, una cambio en la estrategia del arte político frente al anunciado final de todo arte político proclamado por los postmodernos conservadores. De todos los nombres que en aquellos años ochenta contribuyeron a clarificar la situación y a proponer ideas y argumentos para la autocomprensión del mundo del arte me centraré, como ya he anticipado, en Hal Foster. A principios de los años ochenta, un muy joven Foster, aún estudiante de postgrado, se hiciera muy conocido gracias a una antología, todavía hoy muy útil, de textos sobre este asunto ${ }^{13}$, apuntando con bastante

13 H. Foster, The Anti-Aesthetic. Essays on Postmodern Culture, Seattle, Washington: Bay Press, 1993. 
acierto la necesidad de pasar de una estrategia de transgresión a una estrategia de resistencia ${ }^{14}$. El argumento formulado por Foster se resume más o menos así: el programa transgresor de la vanguardia estaba culturalmente determinado e históricamente vinculado a un modelo productivista que se corresponde con una concepción simplista de la ideología que la considera una mera codificación de creencias de clase, y con una cierta idea del arte entendido como instrumento del cambio revolucionario. Los viejos proyectos transgresores han de quedar a un lado en favor de una estrategia de resistencia o interferencia en la que la sociedad ya no es vista, al modo de los marxistas o de la teoría crítica adorniana, como un «sistema total», sino como una coyuntura de prácticas, muchas de ellas contrapuestas, en donde lo cultural es una arena en la que es posible la contestación eficaz. Lo político en el arte contemporáneo occidental sólo sería posible en estos términos de resistencia. Para Foster se trataba, no de cuestionar el componente crítico que la vanguardia tuviera en el pasado -labor para la que ya están los conservadores empleados-, sino que se trataba de ver cómo dicha componente crítica podía reinscribirse en el presente como discurso crítico y de resistencia. Así, pues, se trataba de pasar de la metáfora militar optimista y exultante de una avant garde a la metáfora igualmente militar pero más modesta y circunspecta de résistance $e^{15}$.

Tal concepción no significaba proclamar la «muerte» de la vanguardia, sino poner en cuestión la validez en el presente de dos de sus principios, esto es: en primer lugar, el concepto estructural de «límite» cultural como algo a derribar, y, en segundo lugar, la política de «liberación social» como programa que el arte de vanguardia debe de algún modo emular o estimular. Por lo que hace al primero de estos principios, la transgresión vanguardista suponía de hecho un límite cultural más allá del cual se encontraba lo escandaloso, lo feo, lo imposible. Tal límite era posible en la sociedad estructurada del capitalismo monopolista. En dicha sociedad la transgresión tenía un poder estratégico en la medida que abría compuertas que daban a continentes obscuros y peligrosos para la conciencia. Piénsese en la provocación que representó el primitivismo moderno de unas Demoiselles d'Avignon al devolvernos aquello reprimido por el imperialismo europeo bajo la forma de desafío a la superioridad y autonomía de las tradiciones culturales occidentales. Sin embargo, en las sociedades contemporáneas tardocapitalistas las transgresiones tienen mucho menos efecto

14 H. Foster, «Recodificaciones: hacia una noción de lo político en el arte contemporáneo», en: P. Blanco y otros (eds.), Modos de hacer: Arte crítico, esfera pública y acción directa, Salamanca: Ediciones Universidad de Salamanca, 2001, pp. 95-124. La versión castellana recoge parte de dos artículos aparecidos originalmente en H. Foster, Recodings. Art, Spectacle and Politics, Seattle: Bay Press, 1985.

15 Idem, p. 106. 
debido a que en buena medida han sido barridas las viejas estructuras del yo, la familia, la clase social, la religión y la nación. Resulta hoy difícil provocar y transgredir.

Por otro lado, la liberación social que iba asociada a la vanguardia también había perdido su objeto histórico. Foster pone como ejemplo principal la posición de Foucault ante el psicoanálisis, para quien éste era una de las formas de poder disciplinar que había que poner en cuestión. La «liberación», en tanto que opuesto a la represión, en modo alguno liberaría, sino que por contra estimularía la sujeción cultural a través de los discursos del yo y la sexualidad. El psicoanálisis para Foucault era un aparato disciplinario mediante el que el sujeto se pone en discurso por medio de la confesión en el diván, internalizándose el control social a través de la conciencia ${ }^{16}$.

Para la estrategia de la resistencia, pues, no existen ni los límites que transgredir ni la hipotética liberación. Por el contrario, se trata más bien de «una estrategia deconstructiva basada en nuestro posicionamiento aquí y ahora como sujetos integrados en un entorno de significados culturales y disciplinas sociales ${ }^{17}$. Lo que importa ahora, no es tanto reproducir las representaciones y formas genéricas dadas cuanto investigar los procesos y aparatos que las controlan, no tanto presentar lo criticable mediante un código retórico establecido cuanto recodificar los lenguajes y los medios buscando quebrar los moldes anquilosados de un pensamiento cosificado. Este arte político no avanza mediante transgresiones, sino mediante operaciones de resignificación y recodificación en las que los signos y los símbolos son reevaluados, reinterpretados y redirigidos ${ }^{18}$. De ahí la importancia que para Foster tienen los distintos modelos de prácticas apropiacionistas de aquellos años ochenta. El primer Jeff Koons, Sherry Levine, Dan Graham, etc., serán algunos de los nombres de artistas que en sus prácticas recodificadoras Foster cree descubrir la estrategia de resistencia alternativa a las viejas prácticas ideológicas de la transgresión. Pero justamente en estos artistas, especialmente el primero de ellos, Koons, nos encontramos de lleno ante fenómenos de estetización y neutralización. El propio Foster reconoce que este programa de resistencia no siempre funciona, porque, en el caso de las recodificaciones que buscan restaurar el sentido originario, las «historicistas» digamos, son subsumidas bajo el discurso del arte o la moda y por ello estetizan más que politizan. Esta estetización es finalmente una máscara, 'un disfraz aurático para la mercancía' (Benjamin Buchloh) y / o una coartada vanguardista para convertir lo histórico en un objeto de consumo. Por otro lado, las apropiaciones que persiguen reinscribir el signo en un sistema

16 M. Foucault, Historia de la sexualidad, vol. 1, Madrid: Siglo XXI, pp. 11 y 193.

17 Idem, p. 107.

18 Idem, p. 116. 
contra-mítico «también estetizan, pero bajo el disfraz crítico de la "textualidad". Pese a que quizás pueda reapropiarse de signos, fracasa a la hora de aterrizarlos materialmente. Resultan así desplazados de su sistema original pero no llegan a ningún sistema contra-mítico, el signo deviene aquí un mero significante en un juego textual de lo mismo» ${ }^{19}$. Aunque Foster no apunta a ningún nombre, parece claro que su razonamiento se puede aplicar a artistas apropiacionistas como Levine y sus juegos con las fotografías de Walker Evans o con obras fundamentales de las vanguardias.

Finalmente, pues, aunque Foster realizó un notable esfuerzo teórico para repensar los dilemas de un arte político en la postmodernidad, al final le vemos toreando con dilemas parecidos a los de Adorno. Tampoco las estrategias de resistencia pueden evitar la estetización y la neutralización como un horizonte muy real y poderoso. Por lo demás, Foster está bastante más próximo a Adorno de lo que a primera vista pudiera parecer. Basta con leer su artículo de la época «Contra el pluralismo» ${ }^{20}$ para comprender que su visión dialéctica de la situación del arte contemporáneo adolece del mismo mal hegelomarxista que la adorniana. En aquellos años Foster tampoco había pensado a fondo la relación entre arte y esfera pública y seguía aferrándose a una filosofía (trágica) de la historia. Y con él todo el grupo de October.

\section{III}

Hoy, veinticinco años después de los esfuerzos del joven Hal Foster, las cosas no parecen haber mejorado en absoluto y los discursos de la teoría y la filosofía del arte no acaban de llamar las cosas por su nombre. Hay, sin embargo, algunas excepciones, polémicas, claro es, como es el caso del teórico norteamericano, crítico de arte e historiador Donald Kuspit, quien en sus últimos trabajos ha formulado sin ambages sus puntos de vista acerca de los problemas que nos ocupan. Kuspit defiende una teoría del arte basada en el psicoanálisis. Según dicha teoría, la fuente del arte moderno es la conciencia de la existencia del inconsciente, el viaje del artista hacia la interioridad que iniciara el Romanticismo, y la finalidad del arte es el fomento de la autonomía individual y la libertad crítica, reforzando el ego tanto frente al superego social como frente a los instintos que ahogan la individualidad ${ }^{21}$. Así, la obra de arte es, tanto para

19 Idem, p. 116, nota 45.

20 H. Foster, Contra el pluralismo, Eutopías, Documentos de Trabajo, vol. 186, Valencia: Episteme, 1998.

21 D. Kuspit, The End of Art, Nueva York: Cambridge University Press, 2004, pp. 89 y 14, por ejemplo. Véase también, para las líneas que siguen, «El arte visual y la crítica de arte. 
el artista como para el público, un remedo del diván psicoanalítico, y para el crítico, claro es, un síntoma de una conflictiva vida psíquica que hay que descifrar. En el acto de creación para Kuspit se produce, como sostenía Duchamp ${ }^{22}$, un acto de transferencia del artista al espectador. Transferencia es un término psicoanalítico que se refiere a la tendencia del psicoanalizado a transferir los sentimientos a menudo intensos e incluso dolorosos que experimentó en sus relaciones de la infancia a su relación con el psicoanalista. Duchamp sugería que en el acto creativo el artista transfiere sus sentimientos primitivos a su material, que se convierte así en el médium a través del cual se transfieren al espectador. La transferencia sería, en efecto, el acto creativo básico que convierte el material en arte. El primer paso creativo sería convertir el material en médium. En otras palabras, el médium material reemplazaría al psicoanalista, de modo que crear una obra de arte se convertiría en una especie de autoanálisis del artista. Cada obra particular representaría un encuentro consigo mismo o consigo misma, como si dijéramos. Esto es, sería una sesión de psicoanálisis en la que el artista experimenta y ordena de nuevo sus sentimientos a través del médium de su material. El estudio se convierte en una clínica en la que el artista persigue su curación, aunque todo lo que puede lograr es autoexpresarse estéticamente, reflejarse bajo un disfraz artístico. Por el lado del espectador o receptor nos encontraríamos con algo parecido. La contemplación o recepción de la obra nos confrontaría a cada cual con nuestros conflictos con el superego, nuestras angustias, nuestros deseos inconscientes insatisfechos y con nuestros sentimientos más ocultos. La experiencia de la obra de arte tendría, así, un efecto catártico liberador, aprenderíamos algo acerca de nosotros mismos y ese conocimiento nos daría un quantum de autonomía personal, por pequeño que sea. Prestemos atención, por lo demás, al hecho de que esta concepción encierra necesariamente una visión algo clásica del arte: el arte es un símbolo en un soporte sensible destinado a la contemplación en una experiencia específicamente estética. Esta visión habrá de chocar inevitablemente con muchas de las líneas de desarrollo del arte contemporáneo.

A partir de esta concepción, que ha cultivado y aplicado con enorme coherencia a lo largo y ancho de su obra de crítica y teoría del arte, Donald Kuspit se ve lógicamente empujado a un diagnóstico pesimista de la situación del arte contemporáneo. Tan pesimista, en realidad, que sostiene que hoy en día domina el postarte y sentencia el fin del arte. Ello se debería a que la creación artística

El papel del psicoanálisis», en: D. Kuspit, Signos de Pisque en el Arte Moderno y Postmoderno, Madrid: Akal, 2003, pp. 369-383.

22 The creative act «is comparable to a transference from the artist to the spectator in the form of an aesthetics osmosis taking place trough the inert matter, such as pigment, piano or marble» (1957). 
dominante hoy ya no consiste en aquel remedo clínico del psicoanálisis, por ello tampoco el arte es ya arte, sino sólo postarte, y la recepción se ha convertido en entretenimiento y juego en el que la fuerza ilustradora y desalienadora del arte queda neutralizada. Cuando el arte ya no se nutre de las oscuras fuerzas psíquicas que lo han venido moviendo en los últimos doscientos años y se somete a los dictados meramente sociales, políticos o técnicos externos no puede evitar ser arte neutralizado, mera imagen estética castrada, juego y entretenimiento superficial. La proclamación de la muerte del arte, como es sabido, ha sido un gesto intelectual proclamado por cada generación desde los tiempos del Romanticismo, cuando uno de los primeros críticos de la modernidad, G.W.F. Hegel sostuvo que el arte se encontraba ya después del Arte, esto es, que vivía más allá del momento en que realizó su concepto y que, por tanto, estaba viviendo en la etapa de su superación y disolución en un estado en el que la realidad del mismo ya no se adecuaba a su concepto. El concepto del Arte era el de ser una de las formas del Espíritu Absoluto, concretamente la Verdad presentada en forma sensible, al modo como la Religión o la Filosofía son la Verdad presentada en los medios de la Representación y del Concepto, respectivamente. Para Hegel buena parte del arte de su tiempo se alejaba de la Verdad, era subjetivista, una práctica cultural que tenía cada vez más que ver con la exhibición, el ingenio, la habilidad, la organización del entretenimiento y el tiempo para el juego. La tesis del fin del arte se conceptúa siempre como un desencuentro entre el Concepto de arte y su realidad. Y el problema suele ser que el Concepto de arte puesto sobre la mesa es un determinado concepto del arte. Kuspit no hace nada nuevo respecto a lo que proclamaron Heine y Stendhal después que Hegel, Baudelaire y Huysmanns, Duchamp y los dadaístas, o Heidegger y Adorno. Lo que hace con sólidos argumentos Kuspit es reformular aquella tesis con elementos nuevos basados en su concepción militantemente psicoanalítica.

Para Kuspit buena parte del arte postmoderno de las últimas décadas es simplemente banal, superficial y trivial porque ha perdido toda conexión con esa fuente que es el inconsciente. El que comenzó con esta deriva hacia el postarte (Kaprow) antiestético (Foster) habría sido, sin lugar a dudas, Marcelo Duchamp. Los ready-mades duchampianos o el Gran Vidrio anticiparon ese tipo de obras que son arte y son objetos reales, carentes de dimensión específicamente estética, y cuya función es de carácter intelectual, a menudo moral y política. Frente a la fuerza de las obras de Gauguin, Picasso o Pollock, el arte conceptual en bloque o buena parte del arte pop y del minimalista, así como los correspondientes postconceptualismos, postminimalismos y movimientos postpop no son otra cosa que banales ejercicios de entretenimiento entregados al mercado y el espectáculo. Desde Andy Warhol, el primer «postartista» según 
Kuspit $^{23}$, a Damien Hirst, al más representativo postartista del presente, sólo ha habido un camino de desartización del arte. No es de extrañar lo que le pasó a la instalación de Damien Hirst en una ventana de la galería Mayfair de Londres en octubre de 2001. Un empleado de la limpieza arrambló con todo y la echó a la basura: se trataba de una colección de tazas de café medio vacías, ceniceros llenos de colillas, botellas de cerveza vacías, una paleta de pintura usada, pinceles, envoltorios de caramelos y papeles de periódico extendidos por el suelo. Era la pieza central de una exposición de arte de edición limitada que la Galería Eyestorm ofreció en una fiesta para VIPS en dicho espacio. El pobre encargado de la limpieza no supo ver que se trataba de «un Damien Hirst original», según afirmara luego la señora Reitmaier, responsable de proyectos especiales de la galería. Y es que a veces «el arte imita la vida, quizás hasta demasiado», como dijo Warren Hoge, crítico de arte en el New York Times. Todo lo cual puso a Hirst de lo más contento, al punto de reír más que nadie, al encontrarlo «histéricamente divertido». Para Kuspit la anécdota se eleva inevitablemente a categoría. «Hirst estaba entusiasmado por el carácter de basura de su obra basura, pues al tomarla por vida se confirmaba que su arte trata de las relaciones entre el arte y la vida cotidiana... La vida cotidiana es más interesante que el arte, y el arte es sólo interesante cuando es confundido con la vida cotidiana, aún cuando ello signifique que pierde su identidad como arte, identidad que sólo tenía porque se exponía en un lugar llamado galería de arte y, así, había sido insitucionalizada como arte. El hombre de la limpieza fue claramente el crítico correcto» ${ }^{24}$. La conclusión de Kuspit es clara: lo que no es arte no es arte aunque lo digan las instituciones del mundo del arte. Puede que afirme que critica la vida cotidiana, pero lo hace glamourizando la realidad cotidiana que pretende analizar, reproduciendo mecánicamente la realidad cotidiana misma $\mathrm{y}$, por consiguiente, reafirmándola sin afectarla ni alterar en serio la conciencia del espectador, convirtiéndola en algo banal y castrado.

Con el arte moralista y político Kuspit tiene parecidos problemas. Para él el artista no es el sujeto más indicado para decirnos lo que está bien y lo que está mal. El destino de las obras de arte público de Barbara Kruger o de Jenny Holzer tiene que ver más con la distracción que con la reflexión. Están tan entregadas a los medios técnicos del entretenimiento de masas que parecen asumirlos hasta convertirse en un fin, en espectáculo ${ }^{25}$. El postarte ha substituido el inconsciente por la ideología y la teoría, pero en esta operación las obras de arte se convierten en banales ilustraciones de aquéllas. El supuesto

23 D. Kuspit, The End of Art, p.76. Kuspit sigue a A. Kaprow, Essays on the Blurring of Art and Life, Berkeley: University of California Press, 1993, pp. 97-98.

24 Idem, p. 74.

25 Idem, p. 96-97 
uso moral del arte para la crítica meliorativa y la defensa de causas sociales justas, al abandonar la civilizada idea de que el arte es el espacio privilegiado de la contemplación, ese santuario enfrentado a la barbarie del mundo y, con ella, la renuncia a un espacio psíquico en el que podemos poseernos a nosotros mismos y sobrevivir construyendo nuestra autonomía como individuos, el postarte antiestético nos deja inermes ante las fuerzas del mercado y la sociedad del espectáculo, la supuesta subversión se transmuta en conformidad con lo existente. Es la diferencia entre el arte político de Otto Dix y el postarte político postmoderno. Cuando contemplamos las terribles imágenes de las trincheras en las obras de Dix la transmutación de la muerte y destrucción en una imagen estética nos da cierta perspectiva que es críticamente mucho más efectiva que cualquier informe periodístico de ello. Es más salvífico para el alma por su carácter catártico que cualquier fotografía de guerra. La fotografía puede conmovernos, pero no rescatará los sentimientos dolorosos que despierta en nosotros, que es lo que las imágenes estéticas de Dix hacen en el acto mismo de evocar esos sentimientos. La fotografía nos muestra la escena devastada, pero las imágenes de Dix no sólo muestran la devastación, nos implican en ella, en una compleja dialéctica de identificación y desidentificación, de vinculación forzada y de desvinculación resuelta. ${ }^{26}$

Frente a esta situación Kuspit responde de un modo muy diferente a Hegel, Adorno o Foster. Hegel creía sinceramente que el tiempo del arte había pasado definitivamente y que había que tomarse las cosas tal cual devienen: aunque no tengamos Arte nos queda la Filosofía, y una buena ópera de Rossini siempre será un buen divertimento. Adorno planteaba, con ánimo pesimista, un horizonte de resistencia permanente al triunfo definitivo de la cosificación, un horizonte en el que la memoria debe jugar un papel fundamental. Foster, con ánimo bastante optimista, también formulaba una estrategia de resistencia que, aunque no pudiese librarse siempre de la amenaza de la neutralización, habría de permitir la persistencia del arte como crítica de la sociedad. Kuspit, en fin, en una sintonía muy optimista, cree reconocer en el presente la permanencia del Arte según su concepto en la pintura de las últimas décadas y aboga por un retorno a ésta sin restricciones. Su apuesta se cifra en los que pomposamente denomina los New Old Masters, los nuevos grandes maestros. La nómina de dichos maestros del presente iría desde Lucian Freud y Avigdor Arikha, hasta Vincent Desiderio, Jenny Saville y Odd Nerdrum. Estos artistas no habrían renunciado ni al inconsciente ni a crear imágenes estéticas para ser experimentadas según el mecanismo de la transferencia psicoanalítica. Casi todo

26 Idem, pp. 37-38. Desconozco si Kuspit se ha pronunciado sobre la obra de Jeff Wall, insigne artista postmoderno cuyas fotografías fueron reivindicadas por Susan Sontag como verdadero arte frente al fotoperiodismo en su ensayo Ante el dolor de los demás de 2003. 
lo demás sería ese postarte postmoderno y postestético cuyo destino es, en el mejor de los casos, la neutralización en forma de mercancía para el consumo u ocasionalmente para el espectáculo de entretenimiento de masas.

La propuesta de Kuspit va acompañada del compromiso necesario en el plano de la comprensión e ilustración crítica de la que su obra misma es ejemplo, esto es, de narrar el presente para hacerlo inteligible a todo el mundo. Así, plantea la necesidad de combatir la fetichización y la reificación del arte por medio de una conciencia crítica que no se pliegue al relativismo postmoderno que sólo puede mirar el arte contemporáneo como un puzzle cuyas piezas no encajan ${ }^{27}$. El rechazo del postarte y la defensa de un arte alimentado por inconsciente que encarnarían ciertos pintores contemporáneos sólo es creíble si paralelamente se hace un esfuerzo por explicar el presente, cosa imposible para el postmodernismo. Puesto que toda narrativa se convierte en un lecho de Procusto para el postmodernismo no puede haber ninguna historia del arte postmoderno, la historia ya no es posible. Y sin embargo es absolutamente necesaria. Escribir la historia es necesariamente un acto de reificación y ésta siempre acaba entronizando ídolos, que es lo contrario de la conciencia crítica. Sin embargo, la ausencia de una perspectiva interpretativa con la que acercarse a lo particular convertiría el presente en un permanente rompecabezas sin sentido y la crítica de arte sería una actividad imposible. Kuspit se arriesga a denunciar la elevación de Ana Mendieta al panteón del arte como ejemplo de lo que debe hacer la auténtica crítica de arte, incluso a defender la superioridad de la obra de su maestro Hans Breder, que fue quién fotografió las obras de Mendieta y sus acciones, y cuyas fotografías podemos actualmente comprar en la exclusiva galería LeLong.

¿A dónde nos lleva el planteamiento de Kuspit? Me temo que a toparnos de nuevo con ideas conocidas, esto es, con la creencia en un concepto normativo de arte, en la verdad y en un cuestionamiento de fondo del pluralismo. El arte tiene que ver con la verdad puesto que si en esencia es un modo para conocernos a nosotros mismos, para lustrarnos al modo que el análisis freudiano, el arte auténtico sólo puede ser de un modo correcto, el que se acomode a esta función cognitiva previamente definida. Lo que no se adecue a esta corrección es automáticamente estigmatizado bien como error, falsedad o mentira, o bien cae bajo otra categoría (postarte). En cualquier caso, de la elección de un concepto normativo de arte resulta automáticamente una exclusión de aquello que no concuerda con la elección realizada. La lógica interna de esta posición lleva inevitablemente a cuestionar el pluralismo del arte contemporáneo. Así que, al final, Kuspit no está muy lejos del moralismo de Adorno, aunque aparentemente se encuentre lejos del mandarín de Frankfurt. Al final, ambos confían la

27 D. Kuspit, «The Contemporary and the Historical», en Artnet. 
salvación del individuo al arte. Y tal vez esta misión, desde que la enunció el Romanticismo, le haya venido siempre demasiado grande a las prácticas culturales de tan distintas épocas que englobamos bajo el nombre de «arte». Puede que el arte tenga que ver con la verdad, pero quizás su tarea no es construirla de modo directo y positivo, sino indirecto y negativo, más bien mostrando la no verdad y la relatividad de nuestras verdades heredadas y adquiridas. Encerrar el arte en un concepto ha sido siempre la aspiración de la mayoría de los artistas, los críticos y los filósofos. Pero esa aspiración traiciona necesariamente la naturaleza del arte desde que éste se emancipó de sus funciones tradicionales y emprendió en la época romántica ese viaje a todas partes que le caracteriza. No sólo al Inconsciente, sino también a todos los ámbitos del mundo objetivo y del mundo cultural. Kuspit es un crítico honrado y coherente, pero la debilidad de su posición se manifiesta en la elección de una mayoría de nombres en su lista de artistas cuyas obras caen casi siempre en el kitsch, el manierismo, la falsedad y que carecen de la supuesta fuerza ilustradora que deberían tener, además de ser francamente reaccionarias, como es el caso de Nerdrum o de Desiderio. Entre tanto, Kuspit no parece en condiciones de comprender la grandeza y el valor de las obras de otros grandes artistas contemporáneos como Rachel Whiteread, Jeff Wall, Shirin Neshat, Andreas Gursky o James Turrell, artistas que nos han puesto ante lo nunca visto o nos han mostrado con ojos nuevos aquello que a penas conocíamos, ampliando con ello el ámbito de las posibilidades de nuestra experiencia.

A modo de conclusión, cabría argüir que a la luz de las reflexiones a las que aquí hemos dado la palabra, vemos que la neutralización es un fenómeno reconocido al tiempo que se piensan estrategias para vencerla o al menos resistirse a ella. Lo que parece inevitable en este caso, esto es, cuando se piensa en estrategias de resistencia, es la normatividad de la teoría estética. Se acaba defendiendo un concepto determinado de arte como correcto porque tiene una relación recta con la verdad, y a la luz de una tal elección el mundo del arte contemporáneo aparece como un foro alejandrino donde todo vale e impera el relativismo que es la otra cara de la corrupción impuesta por el dinero y el espectáculo mediático. Sin embargo, parece difícil, viendo las cosas más fríamente, no ver que pese a todos los fenómenos denunciados, el arte, pugnando por librarse de la corona de salvador que le pusieron los románticos, va a seguir su camino mientras nosotros los humanos sigamos el nuestro. El arte no va a tener fin. En cualquier caso, el fantasma de la neutralización parece dispuesto a quedarse entre nosotros por mucho tiempo. 